\title{
Querying the Causal Role of Attitudes in Educational Attainment
}

\author{
Stephen Gorard \\ School of Education, University of Birmingham, Birmingham B152TT, UK \\ Correspondence should be addressed to Stephen Gorard, s.gorard@bham.ac.uk
}

Received 13 September 2012; Accepted 16 October 2012

Academic Editors: M. Reis and D. Tudela

Copyright () 2012 Stephen Gorard. This is an open access article distributed under the Creative Commons Attribution License, which permits unrestricted use, distribution, and reproduction in any medium, provided the original work is properly cited.

\begin{abstract}
This paper synthesizes the evidence on the causal impact of attitudes on educational attainment using a simple four-element model of causation-requiring association, sequence, intervention, and explanation. Overall, there was no clear evidence that intervening to change the educational attitudes of disadvantaged students will lead to enhanced attainment. Some mental concepts, such as external motivation, show promise and could be developed further. Others, like locus of control, show little promise and could even be dangerous if used without care. Given that there are other approaches that can help to overcome the poverty gradient in schools, raising aspirations is not the way for policy to go. The stratification of educational outcomes is more likely to be structural rather than mental. An improved attitude without the competence to do something about it could be ineffective, whereas competence may be sufficient in isolation. The current evidence is that attitudes do not cause variation in attainment, and so policies and practices based on a belief that they do are being, and will continue to be, ineffective. Such policies also present opportunity costs, using budget that could be used for more promising approaches, and leaving the poverty gradient largely untouched for yet another generation.
\end{abstract}

\section{Background}

This paper summarises the findings from part of a larger review of evidence on the causal relationship between attitudes and educational attainment. The immediate background was a report for the Joseph Rowntree Foundation [1] which reiterated that there is a considerable gap between the average recorded school attainment of children from richer and poorer families in the UK-a "poverty gradient." It also showed reasonably substantial correlations between levels of attainment and student and family attitudes to education. Those students with better and more favourable attitudes also tend to perform better in assessments of learning. The problem for policy is to decide whether such attitudes and aspirations are a key link between socioeconomic background and school outcomes, which can be harnessed to improve outcomes for the less well-off.

One of the main reasons for having universal, compulsory and free at point-of-delivery early education in developed countries is to reduce the influence of social, familial, and economic background, so promoting social mobility and a just and equitable society. Yet the stratification of educational outcomes in terms of the socioeconomic status (SES) of individuals persists [2]. Understanding the reasons for the poverty gradient and devising approaches that help reduce it are directly relevant to current policy in the UK and elsewhere. It would be unethical and inefficient to base real-life approaches on one study or on a clearly incomplete picture, even though this happens regularly and internationally. It is accepted that there is a positive correlation between some measures of attitudes and individual attainment at school. A vital next step is therefore an appropriately sceptical consideration of what the available evidence reveals about the possible causal links involved. This is needed to avoid wasted effort and opportunity costs, and to hasten the identification of feasible solutions. Yet, some writers rush from this to the claim that attitudes or mental concepts are fundamental in explaining differential attainment [3]. And there is already considerable policy expenditure committed on the premature assumption that aspirations and attitudes can be influenced to improve educational outcomes. For example, in 2009 the UK government introduced plans to lift the aspirations of 2.4 million children [4]. This is just one of many national, regional, and local initiatives. To what 
extent are proposals like these, and the expenditure they entail, justified by the best available evidence? Do attitudes and aspirations cause educational outcomes?

This paper focuses on seven "mental" concepts, based on definitions found in the literature reviewed. These concepts are somewhat indistinct and variously interrelated, and there are variations in use over time and between regions of the world.

"Motivation" is a reason why an individual makes a decision, and their strength of purpose in carrying these decisions out. An indicator might be a child's reported belief that schooling is important for their future.

"Expectation" refers to what an individual believes will happen in the future. An indicator might be a parent's report of their child's likely success in a forthcoming test. The literature tends to suggest that an expectation is about others whereas an aspiration is for oneself. This paper considers parent expectations for their child.

"Aspiration" refers to what individuals hope, rather than believe,will happen in the future. An indicator might be a child's reported desire to continue with education. This review considers young people's intentions and hopes for themselves.

"Self-concept" is an individual's perception of themselves. An indicator might be a child's perception of the economic status of their family. Some writers break global self-concept down into specific parts.

"Self-esteem" refers to an individual's evaluation of their own worth or goodness. An indicator might be a child's perception of others' beliefs about them. Self-esteem and self-concept are considered together in this paper.

"Self-efficacy" is an individual's belief in their own ability to achieve something. An indicator might be a child's belief about their cognitive abilities.

"Locus of control" refers to an individual's belief that their own actions can make a difference. An indicator might be a child's belief about the importance of making an effort to ensure success. Self-efficacy and locus of control are considered together in this review.

This review is concerned with whether changes in aspirations and attitudes such as these can be shown to cause changes in an individual's level of success in educational assessments of any kind. An indicator of success might be a young child's school readiness, such as the ability to read letters of the alphabet and count to ten, or it might be their qualifications at age $16+$ or their entry into higher education.

\section{Methods}

Electronic searches were conducted in the main databases including ASSIA, Australian Education Index, British Educational Index, ERIC, PsycInfo, Research Papers in Economics, Social Services Abstracts, and Sociological Abstracts. These were supplemented by advertising for relevant research reports, advice from the project Advisory Group, handsearching of recent journal articles, and the existing knowledge of the reviewers. Following a substantial scoping review to test the sensitivity of the search terms, a very inclusive statement of search terms was used for each database, searching for any material published or unpublished that mentioned synonyms for attainment at school plus any of the attitude terms, plus any causal term or causal design. This identified 166,491 reports. From these, we excluded reports that were duplicated, predating 2000, not in English, exclusively concerned with special needs children or students beyond school age, instructional/teaching strategies or generic school improvement, reports that were not based on research, or where the quality of reporting was completely deficient. These successive steps reduced the database to 1,827 reports. This version of the Endnote database is available for other researchers upon request. Only a substantial subset of these pieces can be cited in this paper.

We envisaged a causal link from attitudes to attainment as requiring a clear association between the mental construct and attainment, in the correct sequence, with evidence that changing the strength of the construct leads to changes in attainment, and an explanatory mechanism [5]. If each criterion is seen as necessary (though not individually sufficient) for a causal model, then any study including evidence relevant to at least one of these four criteria can contribute to the search for causal mechanisms. However, it was noticeable that it was possible to devise a plausible explanatory mechanism for the effect of any mental concept, even where there is no empirical evidence of effect, or even where there is good evidence of no effect. This suggests that the theorised mechanism is the least important part of any causal model, and so it is largely ignored in this paper. If it is clear that altering an attitude works to improve attainment with no damaging unintended consequences and at reasonable cost, then it matters less if the mechanism is not understood. On the other hand, even the most convincing explanation possible is of little consequence if the attitude has no discernible or beneficial effect on educational outcomes. Evidence for all three of the other elements-association, sequence and intervention-must be present in order to be confident that any relationship is causal.

In general, there was no consistent reporting of effect sizes in the studies. No two sets of effect sizes occurred for the same intervention across different studies, and so no meta-analysis is possible. Hence, it is also not yet possible to conduct a cost-benefit analysis of interventions in each area.

\section{Results}

The findings are summarised here, under the amalgamated headings presented in the definition of terms, with a further "catch-all" attitude category.

3.1. Parental Expectations. The review found a number of studies all showing a positive link between parental expectations and child's school outcomes [6-8]. Children seem to perform better at school when their mothers, in particular, expect them to [9]. Cook [10] used US National Education Longitudinal Survey (NELS) data, and found a strong association between parental aspiration/expectation and 
student achievement. Hong and Ho [11] involved 77 caregivers enrolled in Head Start, and found that high parental expectations were strongly linked to school readiness scores. Grinstein-Weiss et al. [12] used a sample of over 12,000 children aged 5-17, from three different datasets. Their study found that self-reported parental expectations for their children were associated with student outcomes at school. Jeynes [13], in a review of studies, also found a strong link between school grades and parental expectations (0.9 "effect" size). Fan and Chen [14] reviewed a number of studies and reported a stronger association between parental expectation and achievement than between parental involvement and achievement. Therefore, there is considerable evidence that parental expectations are linked to their children's school outcomes of different kinds and at different stages.

Similarly, this new review found a number of reports relating parental expectations for their child's education to the subsequent attainment of the child [15-22]. Taningco and Pachon [23] used data from the Early Childhood Longitudinal Study (ECLS). They found mother's education and parental expectations to be consistently and positively associated with later test scores. In each of these studies, the association appeared in the correct sequence for a causal relationship.

However, it is remarkable that none of these studies included parental SES or student prior attainment in their analyses. Where such contextual factors are included then the apparent link with expectations weakens, or disappears. Englund et al. [24] found no association between parents' expectations and child school performance in 1st and 3rd grades. Skokut [25] found that only SES was linked to school completion for Latino English language learners in California. Parent expectations, parent-child communication, school connectedness, and extracurricular activities made no difference to either outcome. Even though there are several studies looking at simple associations between parental expectations and outcomes, the link between parental expectations and child success is less stable when viewed in the proper sequence for a causal model with appropriate prior contextual factors.

The review found no controlled interventions explicitly intended to alter parental expectations in order to assess their influence on child's school outcomes. Apparently, no one has reported testing this out. Coupled with the inconclusive data on association, the evidence therefore suggests that anyone with a sole concern to improve educational outcomes for those most at risk should seek an intervention elsewhere. There is no good evidence that changing parental expectations will lead to improved attainment by their children later. Perhaps it is worth funding a rigorous evaluation, but it is not yet an approach to be used in practice or embraced by policy.

3.2. Individual Aspirations and Expectations. The review confirmed the association between children's aspirations and their attainment. Many studies suggest that young people with higher educational aspirations have somewhat higher educational attainment than their peers [26-29]. Blaver [30] looked at 1,391 Hispanic youth from the 2003 Trends in International Mathematics and Science Study (TIMSS), and found that self-reported competence in maths was associated with future educational aspirations, and also with maths achievement. Using Longitudinal Study of Young People in England (LSYPE) data, Cuthbert and Hatch [31] found that the aspirations of young people and their parents were associated with their educational attainment.

Yet several studies in this new paper also revealed evidence that this simple association between aspirations or expectations and school outcomes might be something else. Some reports showed very similar patterns of aspirations for different social groups, such as rich and poor students, and despite their different levels of attainment [32-34]. Marjoribanks [35] used an Australian dataset (LSAY) and found that adding student expectations to a regression model to "predict" educational attainment reduced the apparent association with student SES. This means that each variable acts as a proxy for the other, and any analyses not using SES are in danger of overestimating the association of outcomes with expectations.

The sequence in the relationship between educational outcomes and aspirations is anyway far from clear [36]. Aspirations can be both a predictor of educational achievement and an outcome of it, and might be influenced by self-esteem or self-efficacy, personal traits, experiences and mediating family factors [37, 38], or linked to beliefs about ability [39]. Jacob and Wilder [29] suggest that it is this potential iteration between expectations and attainment that makes it difficult to determine the primary causal structure. Young peoples' aspirations and expectations are not always a constant and can change rapidly during their school years [40]. So it is perhaps not surprising that the studies in this paper that are explicitly about expectations and school outcomes do not provide a clear consensus.

Liu [41] used a nationally representative sample from the Education Longitudinal Study of 2002. Students who retained high stable aspirations from 10th grade to the end of high school were the most likely to continue in education. Liu et al. [42] looked at the progress of 2,000 students from grades 7 to 11, and found that the rate of progress was positively related to the expectations of students in Year 7. However, this study had no measures of SES context. Freeney and O'Connell [43] claim that their evidence reveals that an intention to leave school early is "predicted" by attitudes to school. However, their study uses intention to leave rather than leaving itself as the outcome, so it is really associating one mental concept with another. Croll [44] used the Youth Survey from the British Household Panel Survey, from the mid-1970s to the early 2000s, and claimed that "The results show that most children can express intentions with regard to future participation very early in their secondary school careers and that these intentions are good predictors of actual behaviour five years later" (page 400). Children were asked from the age of 11 onwards whether they wanted to stay on in education after the age of 16 . At age 11 , for example, $67 \%$ of those who gave a definite reply said that they intended to stay on, and $72 \%$ did stay on in fact. But the author seems to have misinterpreted this data. The $72 \%$ and the $67 \%$ are different 
subsets of the sample of children. It is not that the $67 \%$ and a few more all stayed on eventually. In fact any predictions based on these reported intentions at age 11 would be less accurate than simply assuming that all children would stay on (i.e., less than $72 \%$ ).

High-educational aspirations do not predict high attainment for all ethnic groups [45], and so they cannot be a general "cause" of attainment. Bui [46] used NELS data to examine the relationship between educational expectations and academic achievement among 10,261 students in Grades 8,10 , and 12 . The author claimed that a cross-lagged analysis shows that there is evidence of reciprocal effects between educational expectations and academic achievement, but that the path from academic achievement to educational expectations is stronger than, and predetermines, the reverse path. Attainment seems to come first in sequence. Overall therefore, the evidence is mixed on both the association and sequence parts of a causal model.

This new review found no rigorous evaluations of interventions explicitly concerned with raising or lowering aspirations or expectations and so influencing educational outcomes. There, presumably, have been many attempts to intervene with policy or practice to influence aspirations/expectations. None were found as part of a randomised controlled trial or similar. In addition, the review finds some evidence of an association between aspirations and school outcomes, but largely when SES background and prior attainment is not accounted for. The evidence falls short of that needed to assume that individual aspiration is a causal influence. Perhaps the variation in outcomes "explained" by aspiration in models like that of Goodman and Gregg [1] reflects mostly the accuracy of individual's imagined futures, or the quality of the feedback they have received from schools. Aspiration could be an indication of success, not its cause. At present, anyone with a sole concern to improve educational outcomes for those most at risk would be advised to seek an intervention elsewhere. However, if an intervention could be devised that isolated aspiration from other factors, then it might be worth conducting a randomised controlled trial or similar to see whether raising aspirations really does lead to a difference in attainment.

3.3. Individual Motivation. A number of studies have suggested weak associations between reported learner motivation and attainment [47-54]. Hayenga and Corpus [55] found that among 343 middle-school students those reporting strong intrinsic motivation received higher school grades than students with reported extrinsic or mixed motivation. Cheng and Ickes [56] found similar results at college level, with 377 college undergraduates. There is, therefore, limited evidence of an association between motivation or type of motivation and attainment.

On the other hand, several studies reported no association in the correct sequence [57, 58]. Gagné and St Père [59] studied 200 students, and showed that cognitive ability, or IQ, was the strongest single predictor of school achievement. If IQ is included in modelling then any association between individual reported motivation and achievement disappears.
This result is similar to that for parental expectation, where the addition of prior variables reduces the apparent association, and it suggests that motivation is a proxy variable rather than a cause of attainment. Similarly, Schwinger et al. [60] found that motivational strategies were not directly related to GPA. There is little good evidence to support a causal sequence from intrinsic motivation to attainment.

Intriguingly, given the shortage of basic evidence of a causal sequence, this new review found four intervention studies, in which extrinsic motivation was a major independent variable. Three of these concerned financial incentive payments.

Fryer [61] examined the effect of financial (extrinsic) incentives on student achievement. The study analysed data on approximately 38,000 students from public schools in Chicago, Dallas, New York City, and Washington, DC. Students were given monetary payments for performance in school, three times a year within days of verifying their achievement. The study found no statistically significant effects on standardised math or reading outcomes in Chicago, New York City, or Washington, DC. Focus group interviews with students suggest that although students may be excited about the incentives they do not actually know how to improve their grades. This is an important point to note for all attitude and aspiration work. Confidence may be misplaced without competence. However, paying students for inputs into the education production, such as for attendance, good behaviour, doing homework, and wearing their uniforms yielded moderate improvements in reading and maths achievements. Paying students to read books yielded a noticeable increase in reading comprehension. In each of these cases it is reasonable to infer that the students knew what to do (i.e., they understood the school's definition of "good behaviour").

Bettinger [62] evaluated the effects of a Coshocton financial incentive programme, providing external motivation for academic achievement. Students in grades 3 to 6 were paid in gift certificates for every good test result in five core subjects. Each school had two grades from years 3 to 6 randomised to take part. In total, it seems there were 24 treatment and 24 control grades, although the report does not make this easy to confirm. There appeared to be a positive effect on maths scores, with high-scoring students more responsive to the incentives. There was no difference in reading. This may be because extrinsic motivation is more effective for less conceptual tasks. Students can memorise a series of facts, like rote-learning tables or formulae, to prepare them for the tests, but it is more difficult for students to prepare in the short term for comprehension after reading a specific text or writing on a particular subject.

Riccio et al. [63] examined whether offering low-income families cash rewards for engaging in activities related to children's education, family preventive health care, and parental employment improved family and child outcomes. Rewards were allocated to students and other family members, and the educational outcomes of students whose families were randomly assigned to participate were compared with those who were not in the programme. The programme was found 
to be effective in improving the maths test scores of $\mathrm{K}$ 5 students in year two of the study, but the effect size was minimal. It was slightly more effective for high school students.

Motivation is intertwined with other issues such as attitude and self-esteem, and this makes it hard to synthesize the body of evidence available. At present, anyone with a sole concern to improve educational outcomes for those most at risk would be advised to seek an intervention elsewhere. However, there may be enough promise from the work already done, and enough evidence here of an association between extrinsic motivation and school outcomes, to investigate further through a large and rigorous trial, if an appropriate intervention can be devised.

3.4. Individual Self-Concept/Self-Esteem. Some studies have linked academic self-concept to achievement, based on correlational or observational data [64-66]. Zand and Thomson [67] found that African-American adolescents with high levels of self-worth were more likely to report having higher grades at school. Gonzalez-Pienda et al. [68] used data for 503 12- to 18-year-old adolescents, and reported that their self-concept was statistically related to their academic achievement. Singh et al. [69] collected data through a survey in three school divisions in the Southwest region of Virginia, USA. There was a slight association between school outcomes (self-reported grades) and self-concept (at least for White students), and a slightly stronger link between a student's school outcomes and their sense of school belonging. However, in a major and widely-cited reanalysis of such previous work, Baumeister et al. [70, 71] have suggested that high self-esteem, in terms of the global self-concept, is not associated with better performance once other factors are accounted for. Therefore, there is only disputed evidence of an association between self-concept and attainment.

This new review found a large number of studies relating to the order of life-history events involving selfconcepts and attainment [72-75]. Eight of these longitudinal studies presented evidence and models suggesting that selfconcept (and self-esteem to a less extent) do not lead to attainment or participation in the way that a causal model would require [76]. For example, Tang [77] used 12,144 students from the base year, and 2nd and 4th year followup of the US NELS 1988-2000 database. Variables included socioeconomic status, prior achievement, self-concept, locus of control, educational aspirations, parental expectations, parental involvement, peer influence, college plans, average grades, test scores, coursework completion, and educational attainment. Prior attainment and SES were the strongest predictors. Once other measures were accounted for, locus of control and self-concept were not linked to subsequent attainment.

Scott [78] analysed interviews with 11- to 15-year-olds in the sample households in the 1994-1999 British Household Panel Study (BPHS), looking also at their educational achievements in later years (aged 16-19). In context, selfesteem was unrelated to subsequent public examination results. This study is important because the multivariate analysis includes factors like family income, mothers' occupation, family structure, housing tenure, and parental education (all strongly linked to attainment). In fact, the more explanatory variables any study includes in analysis the less likely it seems that a mental concept like self-esteem is associated with educational outcomes.

Chowdry et al. [79] used LSYPE data. They found that around two-thirds of the socio-economic gap in attainment at age 16 can be accounted for by prior attainment at age 11 and long-term family background characteristics. This means that little variation in outcomes is available to be explained by constructs like self-concept, motivation, or locus of control (given that there will inevitably be other determinants and some considerable level of measurement error and missing data). Young people from poorer families did tend to rate their abilities lower than did those from better-off families but, after allowing for evidence on prior attainment at age 11 , the poorer young people had actually tended to overestimate their ability while better-off young people had often underestimated their ability. Therefore, simply increasing self-esteem or locus of control would seem to be unlikely to be effective. It could even be dangerously misleading.

Some small studies have proposed that self-concept led to school outcomes in the correct sequence for a causal relationship [56, 57]. For example, Guay et al. [80] used a sample of 465 primary school children whose progress was followed over 10 years. They found that children who perceived themselves as academically competent in early schooling had higher subsequent school achievement. Marsh et al. [81] used a sample of 5,000 early secondary school students, and presented evidence of a link between academic self-concept and future grades, after taking prior achievement into account. However, there were no other context measures such as SES, and it is important therefore to contrast both of these with the even larger studies above that had more background variables and found no impact from self-concept.

Chamorro-Premuzic et al. [82] assessed 5,957 UK twins aged 9 for cognitive ability, academic achievement, and selfperceived abilities. Once cognitive ability was accounted for, self-perception and achievement at age 9 predicted both selfperception and achievement at age 12. The link between prior achievement and later self-perception was about the same strength as the link between prior self-perception and later achievement. The authors claimed that this was evidence of insight (children's accounts of their previous performance) and self-efficacy (the self-fulfilling or motivational effects of self-beliefs). High-performing students apparently adjust their self-perception upwards, which might have a subsequent influence on their attainment. Perhaps the relationship is reciprocal.

Marsh and O'Mara [83] used Youth in Transition data to present what they call a "definitive test" (page 542) of claims that global self-concept has no effect on attainment but that academic self-concept is reciprocally causally linked. However, even this reciprocal analysis is really only an association, where self-concept "predicts" attainment at next 
stage and so on. No context variables were used so there was a lot of unexplained variation for self-concept measures to soak up. Correlations were as low as 0.14 . Less than $73 \%$ of the sample were still included in analysis by the end point (five years after school graduation). Since school dropout is linked to the academic self-concept, the latter could be acting as a proxy for school attendance.

Pinxten et al. [84] used a sample of 1,753 students who were tracked from Grade 7, through 8, 10, and 12. The authors concluded that the results of causal ordering studies have to be interpreted very carefully as different measures of academic achievement can give different apparent causal patterns between academic self-concept and achievement.

Marsh et al. [85] analysed longitudinal data from two nationally representative samples of German 7th grade (13year-old) students (with 5,649 and 2,264 cases, resp.). The prior self-concept of the student explained some of the variation in subsequent maths interest, school grades, and standardised test scores. The authors concluded that selfconcept is both an effect from and a cause of school attainment.

In summary, the evidence from studies of association and sequence is ambiguous. There are several difficulties. First, the theoretical and empirical distinctions between selfesteem (or global self-concept) and academic self-concept have been radically altered over time as advocates find that one or more operational versions of their ideas are ineffective. Second, some studies now present the hypothesized relationship between self-concept constructs and attainment as reciprocal. However, it has proved difficult to find ways of separating the two hypothesized relationships empirically, and therefore it is not possible to rule out the causation being entirely from achievement to self-concept. Third, a majority of these studies have investigated relationships between academic self-concept and attainment for children in secondary school. Some studies focused on students close to the completion of compulsory education. Therefore, it might be argued that any effects of academic self-concept or of prior attainment are already embedded in the children's prior attainment which is used as a baseline in these studies.

The review found five interventions involving changes to self-concept or self-esteem with attainment, of some sort, as a dependent variable. None provide very strong evidence of a causal link. Three have very few cases, especially when analysed by subgroup in the ways presented by their authors [86-88].

Oyserman et al. [89, 90] studied a US School-to-Jobs intervention, based on the idea that individuals have internal "academic possible selves," but that these are insufficient for success unless they linked with plausible strategies to make them work. The goals of the intervention were, reportedly, to help students develop possible selves, provide them with the strategies to attain these, and insulate them against feared "off-track selves" such as involvement in gangs, drugs, and pregnancy. It was expected that in the long term the behaviour relevant to academic possible selves (e.g., doing homework) would increase, leading to better academic outcomes and grade point averages. Low-income middle-school African-American and Latino students were randomly assigned to an experimental (141) or control group (123). The study concluded that the intervention had direct positive effects on possible selves as well as a direct negative effect on school absences (reducing absences). Intervention effect sizes on attainment (GPA) by end of 9th grade were "small-to-moderate."

Possible reasons for the inconsistent results in this field could be that studies used different instruments for measuring self-concepts, and the questions asked were not comparable, and may even have been measuring different constructs (or indeed nothing at all). They also used different indicators of achievement such as standardised tests or teacher ratings. However, the single biggest difference lies in the use of contextual and possible confounding variables. The more and better these additional measures, the less association is found between self-concepts and school outcomes. It is also possible that academic self-concept and academic performance are measuring nearly the same thing. This is especially so where one's academic self-concept is based on other people's opinion about one's academic performance. For example, Bauemister et al. [70] (page 7) suggested that:

People score high in self-esteem because they respond to a questionnaire by endorsing favorable statements about themselves. The habit of speaking well of oneself does not abruptly cease when the respondent turns from the self-esteem scale to the questionnaire asking for self-report of other behaviors. People who like to describe themselves in glowing terms will be inclined to report that they get along well with others, are physically attractive, do well in school and work, refrain from undesirable actions, and the like. That is how they get high scores in self-esteem, but researchers may easily mistake this identical tendency as evidence that self-esteem predicts or even causes a broad range of positive outcomes.

The evidence on self-concept or self-esteem falls short of that needed to assume that it is a causal influence on attainment. This is largely because so many studies found no association after controlling for prior measures like attainment at an earlier stage of education. Therefore, at this time the paper must conclude that a full causal model has not yet been established. However, there is sufficient promise here for there to be some more work, carefully designed to trial interventions that can separate the impact of selfconcept from all else. There is little point in conducting more longitudinal studies as such, however sophisticated the analysis becomes, since these will be unable to resolve the central issue about causation.

3.5. Individual Self-Efficacy/Locus of Control. This new review found a few studies that showed or suggested a correlation between young peoples' reports of an internal locus of control or high self-efficacy, and their school attainment [91-95]. Hejazi et al. [96] involved 400 US highschool students, selected through cluster random sampling, who completed the Revised Identity Styles Inventory and 
Morgan-Jink Student Efficacy Scales. In general, the results indicated that an informational identity style was positively related to academic achievement, while a diffuse/avoidance identity style was negatively related. The authors proposed that the personality style is the cause of the attainment, through the mediation of academic self-efficacy. However, there are several difficult and hypothetical concepts in such a complex and therefore possibly tenuous chain of reasoning.

In summary, although the evidence is sparse and neither high quality nor large-scale, there is perhaps sufficient here for a prima facie case of a causal model. This new review found four further studies linking self-efficacy/locus of control in a plausible sequence [97, 98]. In the USA, Gifford et al. [99] reported that prior ACT scores and locus of control were both associated with university students' subsequent academic results. Students who entered university with lower scores on the locus of control scale (internals) obtained significantly higher GPAs than those who scored higher (externals) on this same scale. Two further studies suggested that there is no sequence. As discussed in relation to self-concept, Pottebaum et al. [76] presented strong evidence that once other measures such as prior achievement were accounted for, then locus of control was not linked to subsequent attainment. Also, Grabowski et al. [100] found evidence that global self-efficacy was not related to subsequent attainment. Overall, the evidence for a sequence is limited and inconclusive. It is as likely that educational outcomes lead to self-efficacy/locus of control as the reverse.

Where the real underlying difference is actual competence, such that differences in beliefs about competence are largely justified, then it is competence and not selfefficacy that needs to altered through any intervention. Simply making people believe that they are more competent than they actually are may be ineffective or worse. But then making people more competent at gaining positive school outcomes, and so also making them more confident, is almost the same as simply improving their school outcomes. Self-efficacy by itself could be a red herring. Young people from poorer families tended to rate their abilities lower than did those from better-off families but, after allowing for (objective) evidence on prior attainment at age 11, the poorer young people had actually tended to overestimate their ability while better-off young people had underestimated their ability. Therefore, simply increasing locus of control could even be dangerous.

Four interventions were found that related to alterations in self-efficacy or locus of control and subsequent attainment. Together, these studies provide very weak evidence of an impact from self-efficacy. For example, Hughes et al. [101] conducted an intervention aimed at developing students' self-perceptions, academic self-efficacies, and academic performance. It involved the Year 6 students in 12 UK primary schools, six given the intervention, and six used as a control. How cases were selected and allocated is not clear. Psychometric tests (general self-efficacy, subjectspecific self-efficacy, self-esteem, and academic motivation) were administered as measures of self-concept just before the programme and seven months later. The intervention had no effect on self-perception and self-motivation, and a small effect on self-efficacy. Intervention schools had higher KS2 scores, after controlling for KS1 scores. However, this improvement was isolated to SEN (special needs) students, who may have felt better about themselves because of the attention given to them as a result of the trial-a kind of Hawthorne factor. Effect sizes, where they were reported, are small.

Blackwell et al. [102] examined the academic trajectories of learners with different implicit theories of intelligence and other achievement-related beliefs. Using four cohorts of students (373) as they progressed from 7 th to 8 th grade in one public school in New York, academic achievement was measured using a standardised math achievement test. The study showed that students who thought their intelligence was malleable and could be developed were more likely to believe that working hard was necessary and effective in raising achievement, than students who thought that intelligence was fixed. At the beginning of junior high school, and controlling for prior achievement, these students outperformed in maths those who held to the fixed intelligence theory. Blackwell et al. [102] then used an intervention to teach half of the 997 th grade students in a second school the belief that intelligence is malleable. There was a slight gain in achievement for the experimental group, especially those who had not believed in malleable intelligence at the outset. This is a very small sample, and the report is missing key information in places (such as when the initial assessments took place).

Miles [103] used a controlled, pre- and posttest design study to test the effects of a "mastery goal approach" to mathematics instruction on the performance of 8 th grade students. Only 79 students took part, of which only 57 were tested, and it is not clear if the allocation to control and treatment group was randomised. The report suggests that the mastery goal approach to instruction brought about a positive change in students' motivation and achievement, but did not provide evidence of the causal direction.

These interventions form a strange combination of approaches, generally with older students, on a very small scale and with far from convincing results. There is little solid evidence that either self-efficacy or locus of control can influence attainment or educational participation. It is certainly not true to say, as You et al. [104] (page 253) do, that "It is well established that perceived control plays an important role in student academic achievement." At present, anyone with a sole concern to improve educational outcomes for those most at risk would be strongly advised to seek an intervention elsewhere. However, there are some indications here that might be worth pursuing, perhaps starting again at the very beginning and testing the contextualised association between self-efficacy and educational outcomes, and looking for evidence of the sequence from one to the other.

3.6. Other Individual Attitudes. This new review found few studies of association between any other individual attitudes, such as respect for education, and educational outcomes. As a whole these are not convincing that there is any strong 
correlation. Hillman [105] reported an association between positive student attitudes towards engagement with school and their achievement. Abu-Hilal [106] used a sample of 280 Grade 9, 11, and 12 students from one high school in California, and measured their attitudes to school subjects (English, math, science and social studies, and school in general), level of aspiration (how far do you think you will go in school?), and standardised achievement tests in the four core subjects. There was only a very weak association between attitudes and achievement (0.04). Twist et al. [107] found some links between attitudes to reading and reading attainment for 200,000 nine-and 10-year-old children in 41 countries in the Progress in International Reading Literacy Study (PIRLS).

There were four further longitudinal studies on this topic. One suggests a link [108], one is of poor quality [109], and the other two both suggest that the sequence moves from attainment to attitude. This is the wrong order for the desired causal model.

Mattern and Schau [110] involved 458 White 7th and 8th grade students in eight rural schools in northern New Mexico. Data on three attitude constructs and four achievement subscale scores were taken twice-once at the beginning and again at the end of the school year. For boys, the best fit structural model was the no-attitudes path model, suggesting that previous attitudes did not have an important link to postattitudes. Postattitudes were influenced by previous achievement, according to the authors. Boys' prior attitudes did not have a greater link with their later achievement than their prior achievement. Girls' achievement was not linked to their prior attitudes (once their prior achievement was accounted for). In other words, girls' prior science achievement is more strongly linked to their later achievement than their prior attitudes. Therefore, teaching strategies that stress achievement could well lead to an improvement in science but have little effect on attitudes. On the other hand, interventions to develop positive attitudes toward science should result in more positive postattitudes, but would be likely to have no discernible effect on achievement.

$\mathrm{Ma}$ and $\mathrm{Xu}$ [111] analysed data from the Longitudinal Study of American Youth (LSAY) in secondary school grades 7 to 12 . This involved 50 middle and high schools, from each of which about 60 seventh graders were randomly selected, and then followed for six years. The results showed that the cross-lagged link between attitude in grade 7 and achievement in grade 8 was minimal. For an individual's entire secondary school career, achievement preceded, and in the words of the authors "demonstrated causal predominance over," attitudes. Prior achievement significantly predicted later attitude across grades 7-12. Prior attitude, by contrast, did not meaningfully predict later achievement. If this study is valid, an institution's ability to affect students' level of achievement via attitudinal change is minimal [112].

This new review found no school-based study that involved an intervention to improve general attitude and therefore attainment. In summary, the review found little solid evidence that intervening to alter attitudes can lead to improvements in educational outcomes. There is not even a promising foundation for future work here. At present, anyone with a sole concern to improve educational outcomes for those most at risk would be advised to seek an intervention elsewhere.

\section{Conclusion}

4.1. Caveats. This review is predicated on the desire of the funder, the Joseph Rowntree Foundation, to be surer about whether working to improve educational attitudes for less advantaged families would have an effect on school outcomes. However, clearly neither the funders nor the reviewer accepts as a premise that poverty should continue to exist, or that more promising and direct attempts to overcome the transmission of disadvantage should be ignored. Further, there are many ways to improve education that are not explicitly related to attitudes. And improvements in some attitudes may be desirable in their own right, even where they have no effect on school outcomes. Anyway, attainment is important but it is only one possible educational outcome. Others, such as future participation, well-being, preparation for citizenship, resilience, and happiness could be just as important. For example, interventions to make school more pleasant and enjoyable, so enhancing school engagement, may not cash out into improved grades [113]. But this is still an intrinsically good thing to do, and it may lead to other desirable outcomes in terms of the preparation of young people as concerned citizens [114]. Also, given that there are currently few successful large-scale interventions that target poor children directly, using the funds currently spent otherwise spent on educational and psychological interventions of uncertain impact may be the most efficient shortterm way to narrow school readiness gaps [115]. All of these approaches_-and others involving improved teaching, peermentoring, parental involvement, and targeted activities like summer schools — could be as important. These are all just not the subject of this paper.

In some respects, the focus of the search on causal claims means that some cross-sectional studies of association may have been missed in this paper, particularly if they described their findings accurately as associative and not necessarily causal. This means that the full body of evidence on simple associations may be underrepresented. However, this is not a major problem for three reasons. The range of longitudinal studies also provides evidence of association. This paper began with a consideration of the relevant associative evidence presented previously [1]. And most importantly, it is not generally the evidence of association between any attitude and attainment that is deficient (it is the lack of convincingly evaluated intervention work). The review focused on work that was electronically available, reported in English language between January 2000 and January 2011, and that was not exclusively about SEN students. It only searched a subset of all possible databases. Therefore, for these and other reasons, this review must still be regarded as indicative rather than "definitive." Nevertheless, this is the largest existing review for the UK, looking at the evidence for a causal model linking attitudes to school attainment. The 
key point is not whether any studies have been missed (they almost certainly have been), but whether finding any new study would alter the substantive findings. For example, the search yielded several similar studies of the self-concept by one group of authors, whose work is well-represented in this review. Adding extra or earlier pieces by these same authors would not, in all probability, alter the judgements made.

4.2. Implications. Most of the mental constructs covered here have such an unpromising evidence base that it is not worth pursuing them at present, if the only reason for doing so is to improve educational outcomes. Changing attitudes to education is not a suitably cheap way for the state or practitioners to tackle the poverty gradient in schools. The resources currently involved in doing so would be better deployed elsewhere, in initiatives that have more promise.

It could be antieducational and perhaps rather dangerous to create an intervention that made more young people falsely believe that their future was under their control to a large extent. It may be that the world is not actually under their, or indeed anyone's, control. Or, the difference between two types of young people could be genuine, in the sense that individuals with an internal locus of control may have learnt that they can control some things while individuals with external locus may have learnt that they cannot. In this case, merely giving the second group more confidence, affecting their locus of control artificially, could be useless or worse. What would be needed, under these conditions, would be greater competence to control their world-including presumably the pace, style and content of their learning. In that case, differential competence could be the cause both of differences in attainment and of a genuine improvement in locus of control. As shown, self-efficacy or a belief in one's own competence is very similar to locus of control, and faces similar problems.

There is some evidence that child aspirations are already realistic (which is perhaps why they show some signs of correlation with outcomes), and a suggestion that to increase them further might be more than the UK labour market and higher education system can cope with [4]. Nash [116] used Progress at School data from New Zealand, and showed that aspiration is not closely associated with SES background. The aspirations of Pacific students are generally very high, and bear little or no relationship to their scholastic achievements. This means that for a large body of students, aspirations are unstratified by class, ethnic origin, and attainment at school [114]. This is an important point because if aspirations were stratified by SES then raising aspirations for children from lower SES families would be fairer even if the "system" could not cope. But if they are not stratified then falling short of one's early expectations and aspirations might perhaps lead to lower emotional and psychological wellbeing in adulthood [117]. There are, therefore, possible dangers in raising aspirations without raising competence. And if competence is raised, is there still a need to raise aspirations artificially? This is a very difficult issue, and it is not clear that researchers, policy-makers or practitioners have thought through the implications here.
There is also the problem that intentions, aspirations, and expectations are very changeable. While this might seem desirable for any intervention intended to change them, the actual level of volatility makes them unreliable as indicators. Croll [44] found, but did not report as such, that less than $41 \%$ of children expressed same aspiration at least four times when asked annually from Year 7 to Year 11, meaning that the majority of students expressed an intention to stay on in education and an intention not to. So, their intention must be right but is also wrong. In their study, Jacob and Wilder [29] also reported that around 60\% of students in their dataset updated their educational expectations at least once, and that expectations have become less predictive of school attainment over past decades. If there is little link between intentions and real outcomes then there cannot be a good causal model.

It has proved hard to provide definitive answers on the effectiveness of the varied psychological constructs under the heading of aspirations and attitudes. The association between measurements of concepts like expectations, aspiration, self-esteem or locus of control and educational outcomes tends to disappear when high-quality contextual data is available. The strongest claims made for the impact of aspirations and attitudes by authors in this paper tend to emerge from studies in which measures of prior attainment or SES background or cognitive ability are missing. When these datasets have sometimes been reanalysed with fuller contextual data, and have shown a reduced or missing association for any construct, then the original authors have changed the construct. Self-esteem becomes global selfconcept, and then academic self-concept, and then academic self-concept for a specific curriculum area, and so on. It makes their ideas almost impossible to test.

4.3. Future Research. A problem for this paper was that the meaning and utility of several concepts, as used by their exponents, was unclear. Another problem was the interlinked nature of aspirations, attitudes, and outcomes with each other and with SES background factors. This is standard in explanatory social science. However, the problem was compounded by the theoretical fragmentation of many of the supposedly explanatory concepts. Are self-esteem and self-concept the same or different, or is one a component of another? Once authors start to break these items down and have 10 or more different kinds of self-concepts, which can be both causes and effects in the same model, then any theory becomes just about untestable. One very useful way forward in this area would be for the theorists to convert their concepts into specific and testable propositions, setting a plausible context and conditions, and then encouraging independent researchers to try and falsify them. The key is that the advocates must agree to success and failure criteria beforehand to prevent further evasion.

The evidence in most areas is generally too immature at present to estimate the effect sizes or the costs of any type of intervention. So it is important that future work moves towards estimates of both, which can then be broken down 
into estimates of cost-effectiveness for specific subgroups of learners such as low attainers and low SES families.

Much of the work found in this paper on the causes of attainment was conducted in the USA. Its results may be relevant to the UK and elsewhere, but it would be helpful to see rather more of this kind of work in other contexts and cultures. A particular concern is that any area may become dominated by only one style of work, contributing to only one part of the causal model (the longitudinal work on selfconcept is a clear example). One way forward would be for funders to adopt an approach closer to that of US federal funding, via the Institute of Education Science for example. Clearly an intervention study in most of the areas covered here would generally be premature and unethical unless there is a prima facie case that the intervention could be effective. In the same way, it would be unethical not to pursue any promising developments into efficacy trials and, depending on results, into national rollout and monitoring. Inevitably even many promising ideas will not work. But this is no reason not to test them properly, as appears to happen too often at present.

\section{Acknowledgments}

The author would like to thank the Joseph Rowntree Foundation for funding the review on which this paper is based, and Peter Davies, Alan Dyson, John Holmwood, Ruth Lupton, Anna Vignoles and Patrick White for their helpful comments on the report, and above all Beng Huat See for the searches.

\section{References}

[1] A. Goodman and P. Gregg, Poorer Children's Educational Attainment: How Important are Attitudes and Behaviour? Joseph Rowntree Foundation, New York, NY, USA, 2010.

[2] M. Tight, "Widening participation: a post-war score card," British Journal of Educational Studies, vol. 60, no. 3, pp. 211226, 2012.

[3] T. Roth and Z. Salikurluk, "Attitudes and expectations: do attitudes towards education mediate the relationship between social networks and parental expectations?" British Journal of Sociology of Education, vol. 33, no. 5, pp. 701-722, 2012.

[4] R. St Clair and A. Benjamin, "Performing desires: the dilemma of aspirations and educational attainment," British Educational Research Journal, vol. 37, no. 3, pp. 501-517, 2011.

[5] S. Gorard, Research Design: Robust Approaches for the Social Sciences, Sage, London, UK, 2013.

[6] M. Carroll, "Exploring the commitments parents make to their children's education," Dissertation Abstracts International Section A, vol. 60, no. 11, p. 3959, 2000.

[7] F. Wu and S. Qi, "Longitudinal effects of parenting on children's academic achievement in African American families," TheJournal of Negro Education, vol. 75, no. 3, pp. 415-429, 2006.

[8] B. Senler and S. Sungur, "Parental influences on students' self-concept, task value beliefs, and achievement in science," The Spanish Journal of Psychology, vol. 12, no. 1, pp. 106-117, 2009.
[9] R. S. Mistry, J. C. Biesanz, N. Chien, C. Howes, and A. D. Benner, "Socioeconomic status, parental investments, and the cognitive and behavioral outcomes of low-income children from immigrant and native households," Early Childhood Research Quarterly, vol. 23, no. 2, pp. 193-212, 2008.

[10] K. Cook, "Effects of parent expectations and involvement on the school readiness of children in head start," Dissertation Abstracts International Section A, 2010.

[11] S. Hong and H. Z. Ho, "Direct and indirect longitudinal effects of parental involvement on student achievement: second-order latent growth modeling across ethnic groups," Journal of Educational Psychology, vol. 97, no. 1, pp. 32-42, 2005.

[12] M. Grinstein-Weiss, Y. H. Yeo, K. Irish, and M. Zhan, "Parental assets: a pathway to positive child educational outcomes," Journal of Sociology and Social Welfare, vol. 36, no. 1, pp. 61-85, 2009.

[13] W. H. Jeynes, "The relationship between parental involvement and urban secondary school student academic achievement: a meta-analysis," Urban Education, vol. 42, no. 1, pp. 82-110, 2007.

[14] X. Fan and M. Chen, "Parental involvement and students' academic achievement: a meta-analysis," Educational Psychology Review, vol. 13, no. 1, pp. 1-22, 2001.

[15] R. Crosnoe, R. S. Mistry, and G. H. Elder, "Economic disadvantage, family dynamics, and adolescent enrollment in higher education," Journal of Marriage and Family, vol. 64, no. 3, pp. 690-702, 2002.

[16] M. Joussemet, R. Koestner, N. Lekes, and R. Landry, "A longitudinal study of the relationship of maternal autonomy support to children's adjustment and achievement in school," Journal of Personality, vol. 73, no. 5, pp. 1215-1236, 2005.

[17] S. R. Sy and J. E. Schulenberg, "Parent beliefs and children's achievement trajectories during the transition to school in Asian American and European American families," International Journal of Behavioral Development, vol. 29, no. 6, pp. 505-515, 2005.

[18] R. E. Strom and F. J. Boster, "Dropping out of high school: a meta-analysis assessing the effect of messages in the home and in school," Communication Education, vol. 56, no. 4, pp. 433-452, 2007.

[19] K. E. Kiernan and M. C. Huerta, "Economic deprivation, maternal depression, parenting and children's cognitive and emotional development in early childhood," British Journal of Sociology, vol. 59, no. 4, pp. 783-806, 2008.

[20] M. A. Rogers, J. Theule, B. A. Ryan, G. R. Adams, and L. Keating, "Parental involvement and children's school achievement: evidence for mediating processes," Canadian Journal of School Psychology, vol. 24, no. 1, pp. 34-57, 2009.

[21] H. See, "The protective role of home learning activities in the development of head start children's school readiness skills: a longitudinal analysis of learning growth rates from preschool through first grade," Dissertation Abstracts International A, vol. 70, no. 1, 2009.

[22] W. Johnson, M. McGue, and W. G. Iacono, "How parents influence school grades: hints from a sample of adoptive and biological families," Learning and Individual Differences, vol. 17, no. 3, pp. 201-219, 2007.

[23] M. Taningco and H. Pachon, Computer Use, Parental Expectations, \& Latino Academic Achievement, Tomas Rivera Policy Institute, 2008.

[24] M. M. Einglund, A. E. Luckner, G. J. L. Whaley, and B. Egeland, "Children's achievement in early elementary school: 
longitudinal effects of parental involvement, expectations, and quality of assistance," Journal of Educational Psychology, vol. 96, no. 4, pp. 723-730, 2004.

[25] M. Skokut, "Educational resilience among english language learners: examining factors associated with high school completion and post-secondary school attendance," Dissertation Abstracts International Section A, Humanities and Social Sciences, 2010, http://udini.proquest.com/view/educationalresilience-among-pqid:1878465731/.

[26] C. Desforges and A. Abouchaar, "The impact of parental involvement, parental support and family education on student achievements and adjustment: a literature review," Department for Education and Skills Report RR433, 2003.

[27] E. Flouri, "Parental interest in children's education, children's self-esteem and locus of control, and later educational attainment: twenty-six year follow-up of the 1970 British Birth Cohort," British Journal of Educational Psychology, vol. 76, no. 1, pp. 41-55, 2006.

[28] J. R. Reynolds and S. W. Burge, "Educational expectations and the rise in women's post-secondary attainments," Social Science Research, vol. 37, no. 2, pp. 485-499, 2008.

[29] B. Jacob and T. Wilder, "Wilder educational expectations and attainment,” NBER Working Paper 15683, National Bureau of Economic Research, 2010.

[30] A. Blaver, "An examination of gender, home language, selfappraisals, and mathematics achievement among Hispanic youth," Dissertation Abstracts International Section A, 2010.

[31] C. Cuthbert and R. Hatch, Aspiration and Attainment Amongst Young People in Deprived Communities: Analysis and Discussion Paper, DCSF, Cabinet Office Social Exclusion Task Force, Short studies, 2008.

[32] I. Turok, K. Kintrea, R. St Clair, and A. Benjamin, Shaping aspirations: The role of parents, place and poverty-Interim Report, Department of Urban Studies, 2008.

[33] J. McKendrick, G. Scott, and S. Sinclair, "Dismissing disaffection: young people's attitudes towards education, employment and participation in a deprived community," Journal of Youth Studies, vol. 10, no. 2, pp. 139-160, 2007.

[34] A. Calder and R. Cope, Breaking Barriers: Reaching the Hardest to Reach, Prince's Trust, London, UK, 2005.

[35] K. Marjoribanks, "Family background, academic achievement, and educational aspirations as predictors of australian young adults' educational attainment," Psychological Reports, vol. 96, no. 3 I, pp. 751-754, 2005.

[36] S. J. Beal and L. J. Crockett, "Adolescents' occupational and educational aspirations and expectations: links to high school activities and adult educational attainment," Developmental Psychology, vol. 46, no. 1, pp. 258-265, 2010.

[37] L. Gutman and R. Akerman, Determinants of Aspirations, Centre for Research on the Wider Benefits of Learning Research Project 27, Institute of Education, London, UK, 2008.

[38] S. Strand and J. Winston, "Educational aspirations in inner city schools," Educational Studies, vol. 34, no. 4, pp. 249-267, 2008.

[39] S. Phillipson and S. N. Phillipson, "Academic expectations, belief of ability, and involvement by parents as predictors of child achievement: a cross-cultural comparison," Educational Psychology, vol. 27, no. 3, pp. 329-348, 2007.

[40] L. Gottfredson, "Gottfredson's theory of Circumspection, Compromise and Self Creation," in Career Choice and Development, D. Brown, Ed., pp. 85-148, Jossey-Bass, San Francisco, Calif, USA, 4th edition, 2002.
[41] L. Liu, From educational aspirations to college enrollment: a road with many paths [Ph.D. dissertation], Abstracts International Section A, Humanities and Social Sciences, 2010.

[42] K. S. Liu, Y. Y. Cheng, Y. L. Chen, and Y. Y. Wu, "Longitudinal effects of educational expectations and achievement attributions on adolescents' academic achievements," Adolescence, vol. 44, no. 176, pp. 911-924, 2009.

[43] Y. Freeney and M. O'Connell, “The predictors of the intention to leave school early among a representative sample of Irish second-level students," British Educational Research Journal, vol. 38, no. 4, Article ID 563838, pp. 557-574, 2012.

[44] P. Croll, "Educational participation post-16: a longitudinal analysis of intentions and outcomes," British Journal of Educational Studies, vol. 57, no. 4, pp. 400-416, 2009.

[45] S. Strand, "Minority ethnic students in the longitudinal study of young people in englan," Research Report DCSFRR002/DCSF-RB002, Department for Education and Skill, Nottingham, UK, 2007.

[46] K. Bui, "Educational expectations and academic achievement among middle and high school students," Education, vol. 127, no. 3, pp. 328-331, 2007.

[47] K. Singh, M. Granville, and S. Dika, "Mathematics and science achievement: effects of motivation, interest, and academic engagement," Journal of Educational Research, vol. 95, no. 6, pp. 323-332, 2002.

[48] OECD, Student Engagement at School: A Sense of Belonging and Participation, OECD, Paris, Farnce, 2003.

[49] S. B. Robbins, J. Allen, A. Casillas, C. H. Peterson, and H. Le, "Unraveling the differential effects of motivational and skills, social, and self-management measures from traditional predictors of college outcomes," Journal of Educational Psychology, vol. 98, no. 3, pp. 598-616, 2006.

[50] N. Unrau and J. Schlackman, "Motivation and its relationship with reading achievement in an urban middle school," Journal of Educational Research, vol. 100, no. 2, pp. 81-101, 2006.

[51] E. Van de Gaer, G. Van Landeghem, H. Pustjens, J. Van Damme, and A. De Munter, "Impact of students' and their schoolmates' achievement motivation on the status and growth in math and language achievement of boys and girls across grades 7 through 8," Psychologica Belgica, vol. 47, no. 1-2, pp. 5-29, 2007.

[52] R. K. Ream and R. W. Rumberger, "Student engagement, peer social capital, and school dropout among mexican american and non-latino white students," Sociology of Education, vol. 81, no. 2, pp. 109-139, 2008.

[53] M. Quirk, P. J. Schwanenflugel, and M. Y. Webb, "A short-term longitudinal study of the relationship between motivation to read and reading fluency skill in second grade," Journal of Literacy Research, vol. 41, no. 2, pp. 196-227, 2009.

[54] C. Somers, D. Owens, and M. Piliawsky, "A study of high school dropout prevention and at-risk ninth graders' role models and motivations for school completion," Education, vol. 130, no. 2, pp. 348-356, 2009.

[55] A. O. Hayenga and J. H. Corpus, "Profiles of intrinsic and extrinsic motivations: a person-centered approach to motivation and achievement in middle school," Motivation and Emotion, vol. 34, no. 4, pp. 371-383, 2010.

[56] W. Cheng and W. Ickes, "Conscientiousness and self-motivation as mutually compensatory predictors of universitylevel GPA," Personality and Individual Differences, vol. 47, no. 8, pp. 817-822, 2009. 
[57] M. Zanobini and M. Usai, "Domain self-concept and achievement motivation in the transition from primary to low middle school," Educational Psychology, vol. 22, no. 2, pp. 203-217, 2010.

[58] M. Dowson, K. Barker, and D. McInerney, "The chicken and the egg: causal ordering of goals and self-concept and its effect on academic achievement," in Proceedings of the Joint AARE/NZARE Conference, Auckland, New Zealand, December 2003, DOW03773.

[59] F. Gagné and F. St Père, "When IQ is controlled, does motivation still predict achievement?" Intelligence, vol. 30, no. 1, pp. 71-100, 2002.

[60] M. Schwinger, R. Steinmayr, and B. Spinath, "How do motivational regulation strategies affect achievement: mediated by effort management and moderated by intelligence," Learning and Individual Differences, vol. 19, no. 4, pp. 621627, 2009.

[61] R. Fryer, "Financial Incentives and student achievement: evidence from randomised trials," NBER Working 15898, National Bureau of Economic Research, 2010.

[62] E. Bettinger, "Paying to learn: the effect of financial incentives on elementary school test scores," NBER Working 16333, National Bureau of Economic Research, 2010.

[63] J. Riccio, N. Dechausay, D. Greenberg, C. Miller, Z. Rucks, and N. Verma, Toward Reduced Poverty Across Generations: Early Findings from New York City's Conditional Cash Transfer Program, MDRC, New York, NY, USA, 2010.

[64] R. Cervantes, "Self-concept, locus of control and achievement in Mexican American students," Dissertation Abstracts International A: The Humanities and Social Sciences, vol. 65, no. 8, pp. 3168-3169, 2005.

[65] T. Peetsma, T. Hascher, I. van der Veen, and E. Roede, "Relations between adolescents' self-evaluations, time perspectives, motivation for school and their achievement in different countries and at different ages," European Journal of Psychology of Education, vol. 20, no. 3, pp. 209-225, 2005.

[66] S. Skaalvik and E. M. Skaalvik, "Self-concept and self-efficacy in mathematics: relation with mathematics motivation and achievement," Journal of Education Research, vol. 3, no. 3, pp. 255-278, 2009.

[67] D. H. Zand and N. R. Thomson, "Academic achievement among African American adolescents: direct and indirect effects of demographic, individual, and contextual variables," Journal of Black Psychology, vol. 31, no. 4, pp. 352-368, 2005.

[68] J. A. Gonzalez-Pienda, J. C. Nunez, S. Gonzalez-Pumariega, L. Alvarez, C. Roces, and M. Garcia, "A structural equation model of parental involvement, motivational and aptitudinal characteristics, and academic achievement," Journal of Experimental Education, vol. 70, no. 3, pp. 257-287, 2002.

[69] K. Singh, M. Chang, and S. Dika, "Ethnicity, self-concept, and school belonging: effects on school engagement," Educational Research for Policy and Practice, vol. 9, no. 3, pp. 159$175,2010$.

[70] R. F. Baumeister, J. D. Campbell, J. I. I. Krueger, and K. D. Vohs, "Does high self-esteem cause better performance, interpersonal success, happiness, or healthier lifestyles?" Psychological Science in the Public Interest, vol. 4, no. 1, pp. $1-44,2003$.

[71] R. F. Baumeister, J. D. Campbell, J. I. Krueger, and K. D. Vohs, "Exploding the self-esteem myth," Scientific American, vol. 292, no. 1, pp. 84-91, 2005.

[72] J. Green, G. Nelson, A. J. Martin, and H. Marsh, "The causal ordering of self-concept and academic motivation and its effect on academic achievement," International Education Journal, vol. 7, no. 4, pp. 534-546, 2006.

[73] M. P. Neuenschwander, M. Vida, J. L. Garrett, and J. S. Eccles, "Parents' expectations and students' achievement in two western nations," International Journal of Behavioral Development, vol. 31, no. 6, pp. 594-602, 2007.

[74] J. Liew, E. M. McTigue, L. Barrois, and J. N. Hughes, "Adaptive and effortful control and academic self-efficacy beliefs on achievement: a longitudinal study of 1st through 3rd graders," Early Childhood Research Quarterly, vol. 23, no. 4, pp. 515-526, 2008.

[75] N. R. Whitesell, C. M. Mitchell, P. Spicer, and The Voices of Indian Teens Project Team, "A longitudinal study of self-esteem, cultural identity, and academic success among american Indian adolescents," Cultural Diversity and Ethnic Minority Psychology, vol. 15, no. 1, pp. 38-50, 2009.

[76] S. Pottebaum, T. Keith, and S. Ehly, "Is There a causal relation between self-concept and academic achievement?" The Journal of Educational Research, vol. 79, no. 3, pp. 140144, 1986.

[77] W. Tang, "Investigating the factors influencing educational attainment across ethnic and gender groups: structural analysis of NELS:88-2000," Database, Dissertation Abstracts International Section A, 2004.

[78] J. Scott, "Family, gender, and educational attainment in Britain: a longitudinal study," Journal of Comparative Family Studies, vol. 35, no. 4, pp. 565-589, 2004.

[79] H. Chowdry, C. Crawford, and A. Goodman, "The role of attitudes and behaviours in explaining socio-economic differences in attainment at age 16," Institute of Fiscal Studies Working Paper 10/15, 2010.

[80] F. Guay, S. Larose, and M. Boivin, "Academic self-concept and educational attainment level: a ten-year longitudinal study," Self and Identity, vol. 3, no. 1, pp. 53-68, 2004.

[81] H. W. Marsh, O. Köller, U. Trautwein, O. Lüdtke, and J. Baumert, "Academic self-concept, interest, grades, and standardized test scores: reciprocal effects models of causal ordering," Child Development, vol. 76, no. 2, pp. 397-416, 2005.

[82] T. Chamorro-Premuzic, N. Harlaar, C. U. Greven, and R. Plomin, "More than just IQ: a longitudinal examination of self-perceived abilities as predictors of academic performance in a large sample of UK twins," Intelligence, vol. 38, no. 4, pp. 385-392, 2010.

[83] H. W. Marsh and A. O’Mara, "Reciprocal effects between academic self-concept, self-esteem, achievement, and attainment over seven adolescent years: unidimensional and multidimensional perspectives of self-concept," Personality and Social Psychology Bulletin, vol. 34, no. 4, pp. 542-552, 2008.

[84] M. Pinxten, B. de Fraine, J. van Damme, and E. D’Haenens, "Causal ordering of academic self-concept and achievement: effects of type of achievement measure," British Journal of Educational Psychology, vol. 80, no. 4, pp. 689-709, 2010.

[85] H. W. Marsh, O. Köller, U. Trautwein, O. Lüdtke, and J. Baumert, "Academic self-concept, interest, grades, and standardized test scores: reciprocal effects models of causal ordering," Child Development, vol. 76, no. 2, pp. 397-416, 2005.

[86] C. Good, J. Aronson, and M. Inzlicht, "Improving adolescents' standardized test performance: an intervention to 
reduce the effects of stereotype threat," Journal of Applied Developmental Psychology, vol. 24, no. 6, pp. 645-662, 2003.

[87] G. L. Cohen, J. Garcia, V. Purdie-Vaughns, N. Apfel, and P. Brzustoski, "Recursive processes in self-affirmation: Intervening to close the minority achievement gap," Science, vol. 324, no. 5925, pp. 400-403, 2009.

[88] D. M. Gordon, D. K. Iwamoto, N. Ward, R. Potts, and E. Boyd, "Mentoring urban black middle school male students: Implications for academic achievement," Journal of Negro Education, vol. 78, no. 3, pp. 277-289, 2009.

[89] D. Oyserman, D. Bybee, and K. Terry, "Possible selves and academic outcomes: how and when possible selves impel action," Journal of Personality and Social Psychology, vol. 91, no. 1, pp. 188-204, 2006.

[90] D. Oyserman, D. Brickman, and M. Rhodes, "School success, possible selves, and parent school involvement," Family Relations, vol. 56, no. 5, pp. 479-489, 2007.

[91] A. Anderson, J. Hattie, and R. J. Hamilton, "Locus of control, self-efficacy, and motivation in different schools: is moderation the key to success?" Educational Psychology, vol. 25, no. 5, pp. 517-535, 2005.

[92] H. Da, "A research into the causality model affecting junior high school students' english academic achievement," Psychological Science, vol. 28, no. 4, pp. 984-988, 2005.

[93] W. Schulz, "Mathematics Self-Efficacy and Student Expectations: Results from PISA 2003," in Proceedings of the Annual Meeting of the American Educational Research Association, April 2005.

[94] N. Speight, “The relationship between self-efficacy, resilience and academic achievement among african-american urban adolescent students," Dissertation Abstracts International B, vol. 70, no. 12, p. 7840, 2010.

[95] M. Bong, C. Cho, H. S. Ahn, and H. J. Kim, "Comparison of self-beliefs for predicting student motivation and achievement," The Journal of Educational Research, vol. 105, no. 5, pp. 336-352, 2012.

[96] E. Hejazi, M. Shahraray, M. Farsinejad, and A. Asgary, "Identity styles and academic achievement: mediating role of academic self-efficacy," Social Psychology of Education, vol. 12, no. 1, pp. 123-135, 2009.

[97] A. Bandura, C. Barbaranelli, G. V. Caprara, and C. Pastorelli, "Self-efficacy beliefs as shapers of children's aspirations and career trajectories," Child Development, vol. 72, no. 1, pp. 187-206, 2001.

[98] M. S. Yailagh, "Role of motivation and cognition on school performance of high-school students: a structural analysis," Indian Journal of Social Work, vol. 64, no. 1, pp. 50-64, 2003.

[99] D. Gifford, J. Briceno-Perriott, and F. Mianzo, "Locus of control: academic achievement and retention in a sample of university first-year students," Journal of College Admission, vol. 191, pp. 18-25, 2006.

[100] L. J. Schabo Grabowski, K. T. Call, and J. T. Mortimer, "Global and economic self-efficacy in the educational attainment process," Social Psychology Quarterly, vol. 64, no. 2, pp. 164-179, 2001.

[101] A. Hughes, M. Torrance, and D. Galbraith, "Evaluation of the Pacific Institute's, "It's up to me!" intervention for motivational development in students at Key Stage 2," Final Report, Institute for Educational Policy Research and Centre for Educational Psychology Research, Staffordshire University, 2006.
[102] L. S. Blackwell, K. H. Trzesniewski, and C. S. Dweck, "Implicit theories of intelligence predict achievement across an adolescent transition: a longitudinal study and an intervention," Child Development, vol. 78, no. 1, pp. 246-263, 2007.

[103] K. Miles, "Mastery learning and academic achievement," Dissertation Abstracts International Section A, 2010.

[104] S. You, S. Hong, and H. Z. Ho, "Longitudinal effects of perceived control on academic achievement," The Journal of Educational Research, vol. 104, no. 4, pp. 253-266, 2011.

[105] K. Hillman, Attitudes, Intentions and Participation in Education: Year 12 and Beyond. LSAY Briefing Number 20, Australian Council for Educational Research, 2010, ED512541.

[106] M. Abu-Hilal, "A structural model of attitudes towards school subjects, academic aspiration and achievement," Educational Psychology, vol. 20, no. 1, pp. 75-84, 2000.

[107] L. Twist, I. Schagen, and C. Hodgson, Readers and Reading: The National Report for England 2006, PIRLS: Progress in International Reading Literacy Study, NFER, Slough, England, 2007.

[108] Y. Li, J. V. Lerner, and R. M. Lerner, "Personal and ecological assets and academic competence in early adolescence: the mediating role of school engagement," Journal of Youth and Adolescence, vol. 39, no. 7, pp. 801-815, 2010.

[109] A. L. Harris, "Optimism in the face of despair: black-white differences in beliefs about school as a means for upward social mobility," Social Science Quarterly, vol. 89, no. 3, pp. 608-630, 2008.

[110] N. Mattern and C. Schau, "Gender differences in science attitude-achievement relationships over time among white middle-school students," Journal of Research in Science Teaching, vol. 39, no. 4, pp. 324-340, 2002.

[111] X. Ma and J. Xu, "Determining the causal ordering between attitude toward mathematics and achievement in mathematics," American Journal of Education, vol. 110, no. 3, pp. 256281, 2004.

[112] W. Hom, "The link between attitude toward math and math achievement. abstract by willard Hom, director of research \& planning unit, system office, california community colleges," 2011, http://www.ocair.org/files/KnowledgeBase/ willard/MathAttitAb.pdf.

[113] S. Gorard and B. H. See, "How can we enhance enjoyment of secondary school?: the student view," British Educational Research Journal, vol. 37, no. 4, pp. 671-690, 2011.

[114] S. Gorard and E. Smith, Equity in Education: An International Comparison of Student Perspectives, Palgrave, London, UK, 2010 .

[115] G. J. Duncan and K. A. Magnuson, "Can family socioeconomic resources account for racial and ethnic test score gaps?" Future of Children, vol. 15, no. 1, pp. 35-54, 2005.

[116] R. Nash, "Educational Inequality: the special case of Pacific students," Social Policy Journal of New Zealand, no. 15, pp. 69-86, 2000.

[117] J. Hardie, How aspirations areformed and challenged in the transition to adulthood and implications for adult well-being [Ph.D. dissertation], 2011, http://gateway.proquest.com/open url\%3furl_ver=Z39.88-2004\%26res_dat=xri:pqdiss\%26rft_ val_fmt=info:ofi/fmt:kev:mtx:dissertation\%26rft_dat=xri: pqdiss:3366345. 

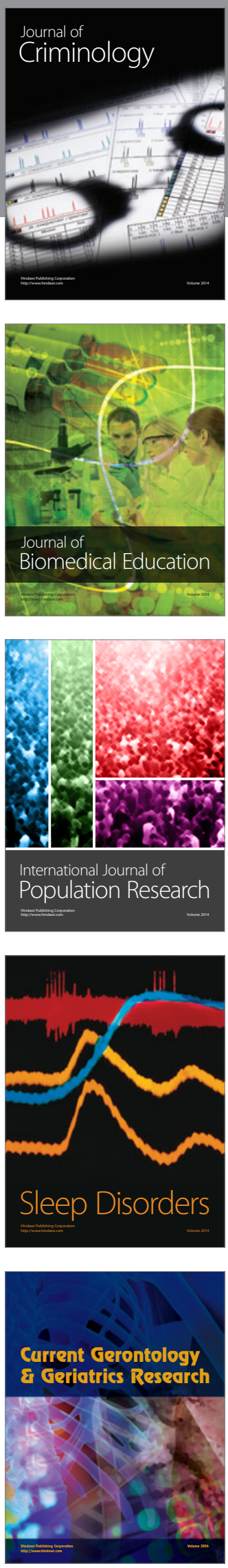
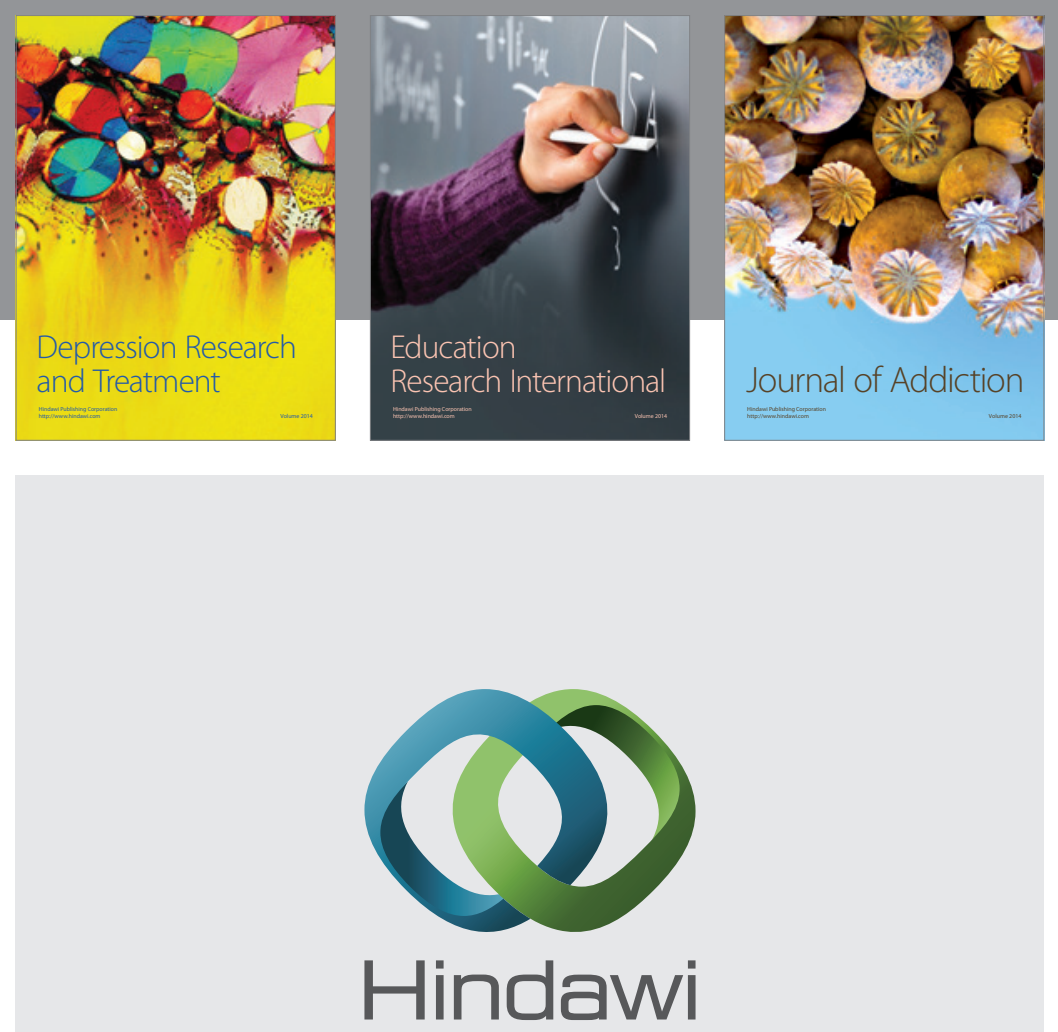

Submit your manuscripts at

http://www.hindawi.com

Child Development Research
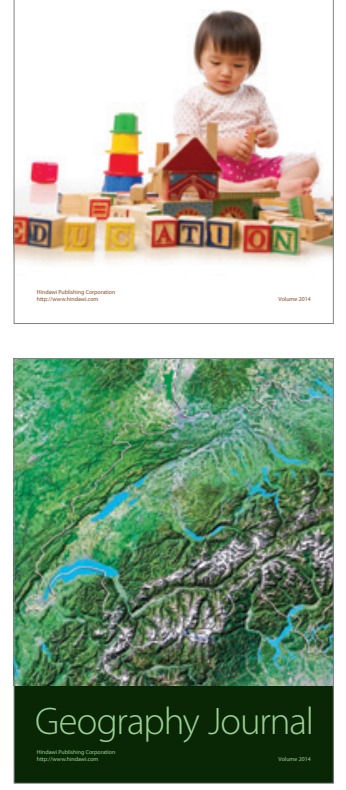

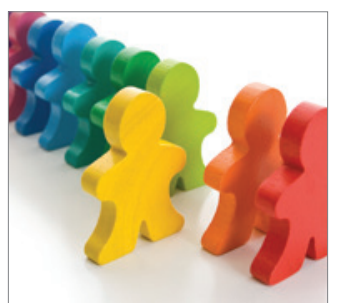

Autism

Research and Treatment
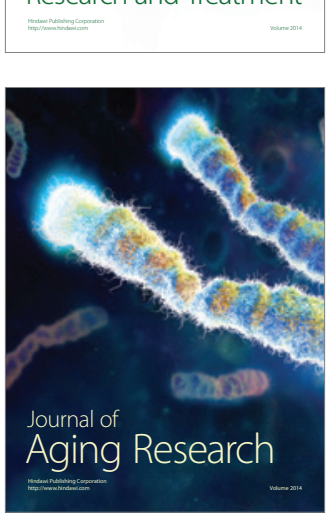
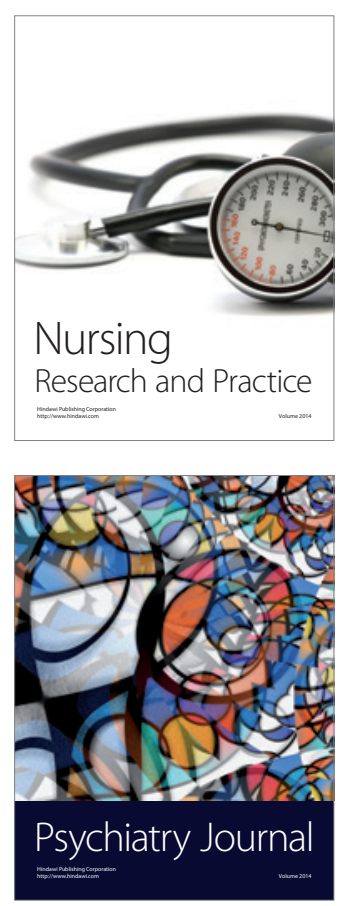
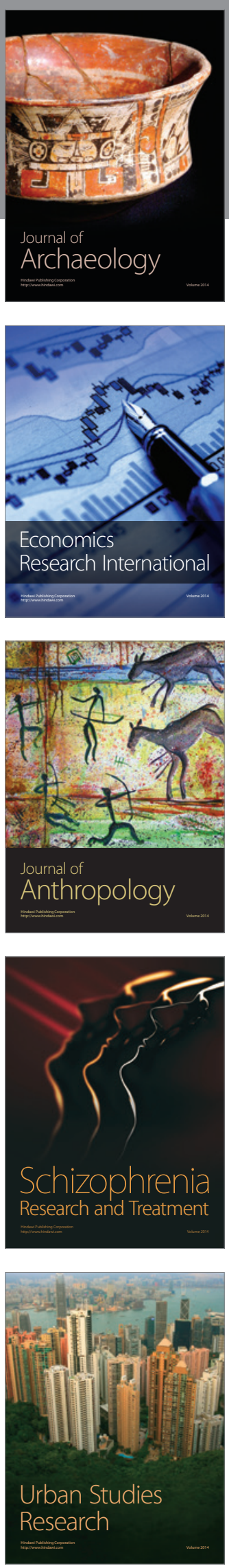